\title{
Impact of T-cell costimulation modulation in patients with undifferentiated inflammatory arthritis or very early rheumatoid arthritis: a clinical and imaging study of abatacept (the ADJUST trial)
}

\author{
P Emery, ${ }^{1} \mathrm{P}$ Durez, ${ }^{2} \mathrm{M}$ Dougados, ${ }^{3} \mathrm{C}$ W Legerton, ${ }^{4} \mathrm{~J}-\mathrm{C}$ Becker, ${ }^{5} \mathrm{G}$ Vratsanos, ${ }^{5}$ \\ H K Genant, ${ }^{6,7}$ C Peterfy, ${ }^{7}$ P Mitra, ${ }^{5}$ S Overfield ${ }^{5} \mathrm{~K} 0 \mathrm{i}^{5}{ }^{5} \mathrm{R}$ Westhovens ${ }^{8}$
}

\begin{abstract}
${ }^{1}$ Academic Unit of
Musculoskeletal Disease,

University of Leeds, Leeds, UK ${ }^{2}$ Cliniques Universitaires SaintLuc, Université Catholique de Louvain, Brussels, Belgium ${ }^{3}$ Hôpital Cochin, Descartes University, Paris, France

${ }^{4}$ Low Country Research Center Charleston, USA

${ }^{5}$ Bristol-Myers Squibb,

Princeton, USA

${ }^{6}$ University of California, San Francisco, California, USA ${ }^{7}$ SYNARC, Inc, San Francisco, California, USA

${ }^{8} \mathrm{UZ}$ Gasthuisberg, Leuven, Belgium
\end{abstract}

Correspondence to Professor P Emery, Leeds Institute of Molecular Medicine,Chapel Allerton Hospital, Chapeltown Road, Leeds LS7 4SA, UK; p.emery@ leeds.ac.uk

Accepted 30 October 2009 Published Online First 23 November 2009

\begin{abstract}
Background Several agents provide treatment for established rheumatoid arthritis (RA), but a crucial therapeutic goal is to delay/prevent progression of undifferentiated arthritis (UA) or very early RA.

Objective To determine the impact of T-cell costimulation modulation in patients with UA or very early RA.

Methods In this double-blind, phase II, placebocontrolled, 2-year study, anti-cyclic citrullinated peptide (CCP)2-positive patients with UA (not fulfilling the ACR criteria for RA) and clinical synovitis of two or more joints were randomised to abatacept $(\sim 10 \mathrm{mg} / \mathrm{kg})$ or placebo for 6 months; the study drug was then terminated. The primary end point was development of RA (by ACR criteria) at year 1 . Patients were monitored by radiography, MRI, CCP2, rheumatoid factor and 28 joint count Disease Activity Score (DAS28) over 2 years.
\end{abstract}

Results At year 1, 12/26 (46\%) abatacept-treated versus 16/24 (67\%) placebo-treated patients developed RA (difference (95\% Cl) $-20.5 \%(-47.4 \%$ to $7.8 \%)$ ). Adjusted mean changes from baseline to year 1 in Genant-modified Sharp radiographic scores for abatacepttreated versus placebo-treated patients, respectively, were 0 versus 1.1 for total score, and 0 versus 0.9 for erosion score. Mean changes from baseline to year 1 in MRI erosion, osteitis and synovitis scores were 0, 0.2 and 0.2 , respectively, versus $5.0,6.7$ and 2.3 in the abatacept versus placebo groups. Safety was comparable between groups; serious adverse events occurred in one patient (3.6\%) in each group.

Conclusion Abatacept delayed progression of UA/very early RA in some patients. An impact on radiographic and $\mathrm{MRI}$ inhibition was seen, which was maintained for 6 months after treatment stopped. This suggests that it is possible to alter the progression of RA by modulating T-cell responses at a very early stage of disease.

Trial registration number NCT00124449.

The management of rheumatoid arthritis (RA) improved dramatically following the introduction of biological treatments ${ }^{12}$ and the increased focus on early intensive treatment. ${ }^{13}$ Despite these advances, current treatment requires chronic use of immunomodulatory agents, and prevention of the progression of early disease remains an important therapeutic goal.

Patients often present during an early undifferentiated phase of arthritis, and one of the challenges faced by rheumatologists (and clinical trial designers) is the classification of these patients. Seropositivity for anti-cyclic citrullinated peptide (CCP) is a useful biomarker in these patients, and indicates a high likelihood of progression to persistent and erosive disease. ${ }^{4}$ Recent advances in our understanding of the genetics of RA susceptibility suggest that anti-CCP-positive RA may actually represent a distinct disease subset. ${ }^{5}$ Given the strong predictive value of antiCCP, it is particularly relevant to examine patients with early disease who are positive for this autoantibody.

Two previous studies have investigated the possibility of preventing disease progression in groups with very early arthritis. In the PROMPTstudy (PRObable rheumatoid arthritis: Methotrexate versus Placebo Treatment study), ${ }^{6}$ methotrexate monotherapy delayed progression to definite RA compared with placebo in a cohort of patients with undifferentiated arthritis (UA) with "probable RA". Structural progression was slowed relative to placebo; however, remission rates were comparable between groups. ${ }^{6}$ The impact of antitumour necrosis factor therapy has recently been examined in patients with poor prognosis UA. ${ }^{7}$ In a small cohort of patients, a short course of infliximab treatment did not increase remission rates or slow progression to definite RA compared with placebo.

Several lines of evidence highlight a role for $\mathrm{T}$ cells in the initiation of immunopathology, suggesting that $\mathrm{T}$-cell modulation may be an effective strategy to prevent disease progression. HLA molecules play an integral role in T-cell activation, and shared epitope HLA alleles are associated with the development of anti-CCP antibodies $^{4}$ and anti-CCP-positive RA. ${ }^{5}$ Biopsy evidence demonstrates a predominance of activated $T$ cells in active synovial joints, ${ }^{89}$ and RAlike symptoms are induced in immunodeficient mice following adoptive transfer of synovial $T$ cells from patients with RA. ${ }^{10}{ }^{11}$ There is evidence of a specific therapeutic window for treatment; early synovitis destined to develop into RA is characterised by a distinct and transient synovial fluid cytokine profile, including several T-cell cytokines. ${ }^{12}$ Abatacept modulates naïve $\mathrm{T}$-cell activation and downstream cytokine production. ${ }^{13}$ It is a fully human, soluble fusion protein, which consists of the extracellular domain of human cytotoxic T-lymphocyte-associated antigen-4 (CTLA-4) linked to the Fc portion of human immunoglobulin online under the BMJ Journals unlocked scheme, see http:// ard.bmj.com/info/unlocked.dtl 
Table 1 Baseline demographics and clinical characteristics

\begin{tabular}{|c|c|c|}
\hline Demographics/characteristics & $\begin{array}{l}\text { Abatacept } \\
(\mathrm{n}=28)\end{array}$ & $\begin{array}{l}\text { Placebo } \\
(\mathrm{n}=28)\end{array}$ \\
\hline Age (years) & $44.8(10.9)$ & $44.7(12.1)$ \\
\hline Gender, female, n (\%) & $20(71.4)$ & $20(71.4)$ \\
\hline Ethnicity, Caucasian, n (\%) & $25(89.3)$ & $23(82.1)$ \\
\hline \multicolumn{3}{|l|}{ Geographical region, n (\%) } \\
\hline Europe & $17(60.7)$ & $21(75.0)$ \\
\hline North America & $6(21.4)$ & $5(17.9)$ \\
\hline South America & $5(17.9)$ & $2(7.1)$ \\
\hline Disease duration (months) & $8.8(4.2)$ & $7.1(4.4)$ \\
\hline \multicolumn{3}{|l|}{ Number of ACR criteria met, $\mathrm{n}(\%)^{*}$} \\
\hline 1 & $5(17.9)$ & $2(7.1)$ \\
\hline 2 & $6(21.4)$ & $9(32.1)$ \\
\hline 3 & $17(60.7)$ & $16(57.1)$ \\
\hline \multicolumn{3}{|l|}{ Number of joints with arthritis, $\mathrm{n}(\%) \dagger$} \\
\hline 1 & $2(7.1)$ & $2(7.1)$ \\
\hline $2-4$ & $20(71.4)$ & $24(85.7)$ \\
\hline$\geqslant 5$ & $5(17.9)$ & $2(7.1)$ \\
\hline Patients with erosions, $\mathrm{n}(\%)$ & $15(53.6)$ & $16(57.1)$ \\
\hline Radiographic erosion score & $3.2(3.5)$ & $3.8(3.3)$ \\
\hline Radiographic JSN score & $0.1(0.4)$ & $0.3(0.9)$ \\
\hline Radiographic total score & $3.3(3.6)$ & $4.0(3.6)$ \\
\hline Physical function (HAO-DI) & $0.8(0.6)$ & $0.8(0.6)$ \\
\hline Levels of CRP (mg/dl) & $1.12(1.43)$ & $1.07(1.60)$ \\
\hline Rheumatoid factor (\% positive) & $24(85.7)$ & $20(71.4)$ \\
\hline DAS28 (CRP) & $3.6(1.1)$ & $3.4(0.9)$ \\
\hline \multicolumn{3}{|l|}{ Antirheumatic drugs } \\
\hline Corticosteroids (oral and/or injectable) & $5(17.9)$ & $3(10.7)$ \\
\hline Corticosteroids (oral $<10 \mathrm{mg} /$ day) & $4(14.3)$ & $2(7.1)$ \\
\hline NSAIDs & $22(78.6)$ & $25(89.3)$ \\
\hline
\end{tabular}

Data are presented as mean (SD), unless otherwise specified.

${ }^{*}$ One patient in the placebo group was later discovered to have had rheumatoid arthritis at baseline, and was withdrawn from the study; †one patient in the abatacept group had no synovitis at baseline.

ACR, American College of Rheumatology; CRP, C-reactive protein; DAS28, 28 joint count Disease Activity Score; HAQ-DI, Health Assessment Questionnaire-Disability Index; JSN, joint space narrowing; NSAID, non-steroidal anti-inflammatory drug.

G1. The CTLA-4 portion of the molecule interrupts the CD80/ CD86:CD28 costimulatory signal, mimicking a native homoeostatic mechanism of T-cell downregulation. In an experimental rat model, prophylactic administration of abatacept inhibited the onset of collagen-induced arthritis. ${ }^{14}$

Here, for the first time, the ability of T-cell modulation to alter the course of disease progression in patients with UA or very early RA was tested by assessing the efficacy of abatacept compared with placebo in a patient population who did not fulfil the American College of Rheumatology (ACR) criteria for RA and who were anti-CCP2 positive.

\section{PATIENTS AND METHODS \\ Patients}

Eligible patients were aged $\geq 18$ years, met at least one, but no more than three of the ACR criteria required for RA diagnosis, ${ }^{15}$ had symptomatic clinical synovitis of at least two joints and did not meet the classification criteria for any other rheumatic disease. Eligible patients were anti-CCP2 positive and had symptom duration (onset of UA to enrolment) of $<18$ months. Patients were excluded if they had received prior biological therapy or treatment with a disease-modifying antirheumatic drug. Corticosteroid treatment was reduced to $\leq 10 \mathrm{mg}$ prednisone (or equivalent) daily for 28 days, and was stabilised for $\geq 25 / 28$ days before study entry.

The ADJUST trial (Abatacept study to Determine the effectiveness in preventing the development of rheumatoid arthritis in patients with Undifferentiated inflammatory arthritis and to evaluate Safety and Tolerability) was approved by the appropriate institutional review boards/independent ethics committees, and was carried out in accordance with the ethical principles of the Declaration of Helsinki. All patients gave written, informed consent.

\section{Study protocol}

This was an international, phase II, randomised, double-blind, placebo-controlled, exploratory study (ClinicalTrials.gov identifier: NCT0012444916). Patients from 21 sites in North America, Europe and South America were randomised 1:1 to receive abatacept at the approved dose of $\sim 10 \mathrm{mg} / \mathrm{kg}$ (according to weight range) or placebo for 6 months, after which treatment was terminated. Randomisation was stratified for the presence of erosions. Abatacept was administered via a $30 \mathrm{~min}$ intravenous infusion on days $1,15,29,57,85,113,141$ and 169 . Follow-up assessments continued over 18 months. Patients, sites and the central laboratory conducting radiographic assessment remained blinded to treatment assignments until the end of the 2-year study period.

Non-steroidal anti-inflammatory drugs or stable low-dose oral corticosteroids ( $\leq 10 \mathrm{mg}$ prednisone equivalent daily) were permitted, but disease-modifying antirheumatic drugs or biological therapies were not. Patients who discontinued could receive the standard of care.

\section{Primary end point}

The primary end point was the proportion of patients who had developed RA defined by the 1987 ACR criteria ${ }^{15}$ at year 1 . Patients who discontinued prematurely owing to lack of efficacy were also considered as having developed RA, and were included in the primary end point.

\section{Radiographic assessment}

Radiographs of both hands/wrists and feet were taken at baseline, month 6, and years 1 and 2 for patients who remained in the study. Digitised images were read at a central facility by two independent expert radiologists blinded to treatment allocation, clinical response and chronological order of radiographs. The Genant-modified Sharp scoring system was used to assess radiographs for changes in total score (TS), erosion score (ES) and joint-space narrowing (JSN) score. ${ }^{17} 18$

\section{Magnetic resonance imaging assessment}

Eligible patients from EU study sites were assessed using gadolinium-enhanced magnetic resonance images of the hand/ wrist. Eligibility was determined by the site radiologist (contraindications included claustrophobia, weight $>250 \mathrm{lb}(114 \mathrm{~kg})$ and allergy or prior exposure (within $72 \mathrm{~h}$ ) to a contrast agent). The hand/ wrist with the most prominent clinical synovitis was selected, and MRI evaluations were performed within 2 weeks before first dose of study drug. Assessments were repeated at month 6 and year 1 . Images were acquired with $1.5 \mathrm{Tesla}(\mathrm{T})$ whole-body MRI scanners equipped with commercial imaging coils. The wrist and metacarpophalangeal joints were scanned separately. Scans included coronal T1-weighted, three-dimensional gradient-echo, with spectral fat suppression (flip angle $=30^{\circ}$, repetition time $=33 \mathrm{~ms}$, echo time $=12 \mathrm{~ms}$, field of view $=120 \mathrm{~mm}$, matrix $=512 \times 192$, slice thickness $=1.5 \mathrm{~mm}$ with no interslice gap) before and after intravenous injection of gadolinium diethylenetriamine penta-acetic acid $(0.1 \mathrm{mmol} / \mathrm{kg})$ contrast material; and coronal fast short-tau inversion recovery (inversion time $=150 \mathrm{~ms}$, repetition time $=4500 \mathrm{~ms}$, echo time $=30 \mathrm{~ms}$, echo train length $=8$; field of view $=120 \mathrm{~mm}$, 


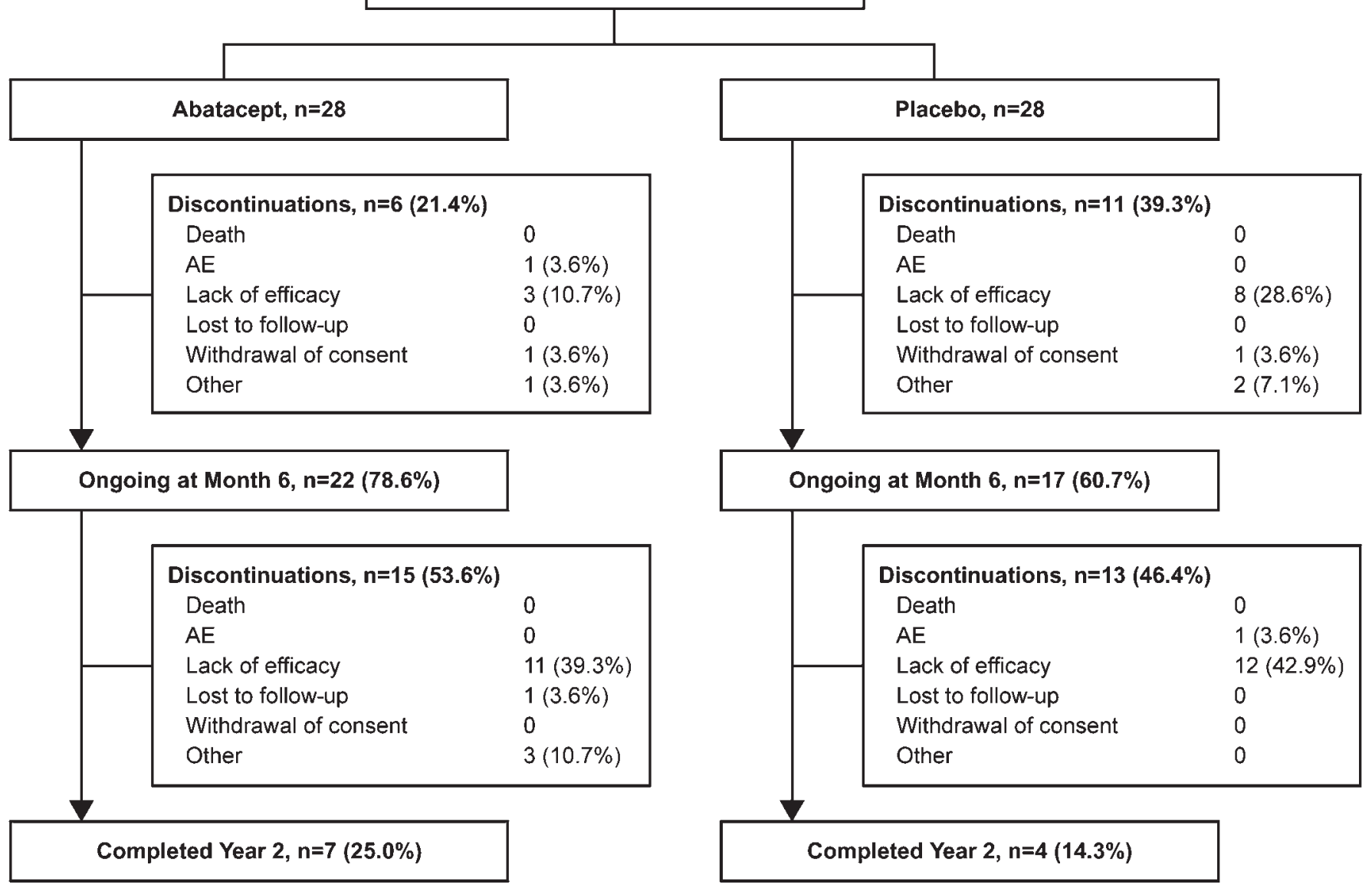

Figure 1 Patient disposition over 2 years. $A E$, adverse event.

matrix $=256 \times 192$, slice thickness $=3 \mathrm{~mm}$ ). Magnetic resonance images were scored for bone erosion, osteitis and synovitis according to the RAMRIS $\operatorname{method}^{19}$ by a single, central radiologist blinded to treatment allocation, clinical response and chronological order of the images.

\section{Biomarker assessments}

Serum samples were taken at baseline, month 6, and years 1 and 2; anti-CCP2 antibody and rheumatoid factor (RF) levels were assessed by enzyme-linked immunosorbent assay.

\section{Clinical efficacy assessment}

A Kaplan-Meier analysis was performed on the time to discontinuation owing to lack of efficacy. Lack of efficacy was determined by the treating doctor, as recorded on the patient's case report form. Secondary clinical end points included 28 joint count Disease Activity Score (DAS28) based on C-reactive protein levels (with remission defined as DAS28 (CRP) $<2.6^{16}$ ) and swollen and tender joints, assessed using a 28-joint count.

\section{Safety}

Safety assessments were performed monthly for 6 months and up to 56 days after the last dose of study drug, and then every 3 months up to year 2. Data presented here include the 6-month treatment period plus 56 days of follow-up.

\section{Sample size calculation}

Sample size was based on the primary comparison between the proportion of abatacept- and placebo-treated patients with RA at year 1, and was not computed with the intention of having adequate size to perform formal statistical tests. With a sample size of 25 patients in each arm, the $95 \%$ two-sided confidence interval (CI) half-width was 0.16 for the placebo group and 0.19 for the abatacept group. This power estimate assumed an incidence of RA of $80 \%$ in the placebo group and $40 \%$ in the abatacept group at year 1 .

\section{Data analyses}

Owing to the exploratory nature of this study, analyses were descriptive; formal statistical testing to generate $p$ values for comparisons between treatment groups was not planned or conducted.

For the primary end point, patients who discontinued before the 1-year assessment for reasons other than lack of efficacy were excluded (predefined in the study protocol). Radiographic, MRI, serology and clinical analyses were based on all patients who remained in the trial and had data available at baseline and the visit of interest (as observed). For radiographic data, adjusted mean changes in TS, ES and JSN were based on an analysis of the covariance model, with change from baseline as a dependent variable and baseline value and treatment group as covariates. For serum levels of anti-CCP2 autoantibodies and 
A)

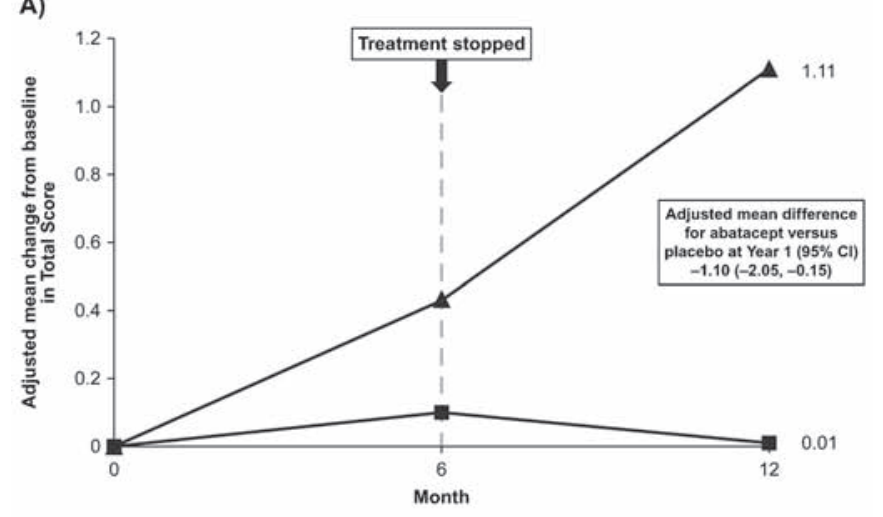

B)

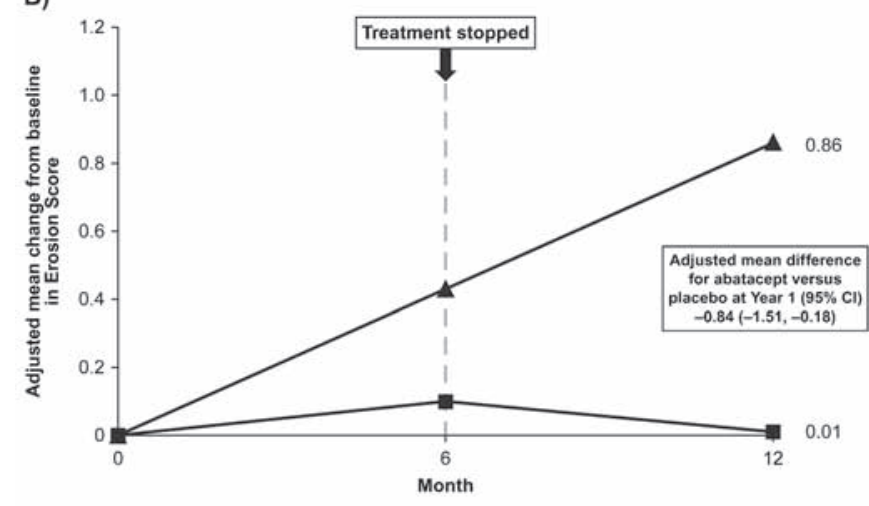

C)

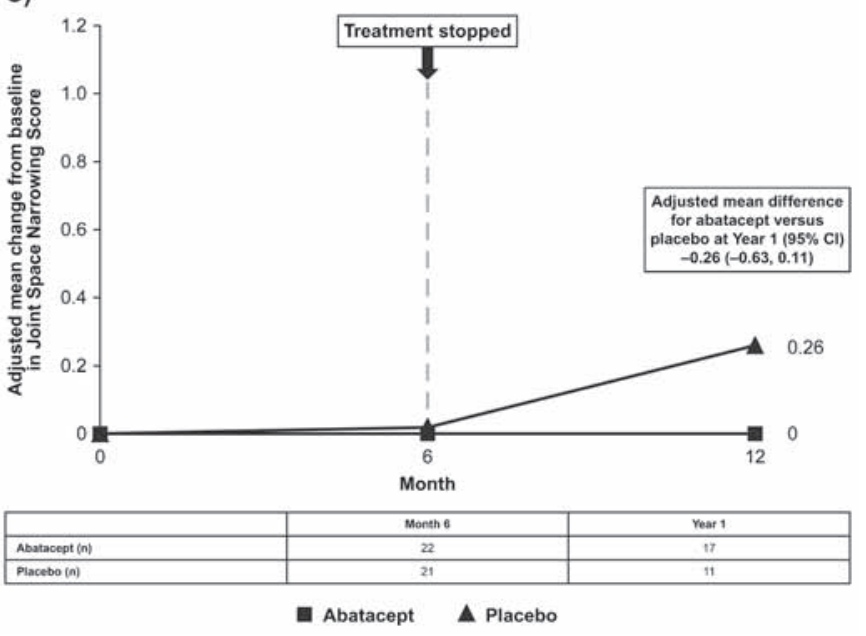

Figure 2 Radiographic progression. Adjusted mean change from baseline to month 6 and year 1 in (A) total score, (B) erosion score and (C) joint-space narrowing score. Data are based on the intention-to-treat population, using data available at the visit of interest (as observed).

RF, point estimates and 95\% CIs were calculated. Exact CIs were calculated using an "unconditional exact confidence interval for the difference of proportions" procedure, from StatXact (Cytel).$^{20}$ For the Kaplan-Meier analysis, an event was defined as discontinuation due to lack of efficacy. The time to event was the number of days between first study drug administration and discontinuation (or the study completion date). Patients who discontinued for reasons other than lack of efficacy were censored at the time of discontinuation. For DAS28 and joint counts, percentages were calculated based on all patients who remained in the trial.

\section{RESULTS}

Baseline demographics and disease characteristics

A total of 56 patients were randomised and treated, and baseline demographics and clinical characteristics were similar between the groups (table 1). Overall, patients had a mean symptom duration of 7.9 months, with a mean C-reactive protein level of $1.1 \mathrm{mg} / \mathrm{dl}$. At baseline, $55.4 \%$ of patients had at least one erosion; all patients were anti-CCP positive and $78.6 \%$ were RF seropositive. Overall, 12.5, 26.8 and $58.9 \%$ patients met one, two or three of the ACR criteria for RA at study entry, respectively.

\section{Patient disposition}

Figure 1 shows the patient disposition. Over 6 months of treatment, $6 / 28(21.4 \%)$ patients in the abatacept group and $11 / 28(39.3 \%)$ patients in the placebo group discontinued; of these, three $(10.7 \%)$ and eight $(28.6 \%)$ were owing to lack of efficacy, respectively. After treatment cessation, from month 6 to year $2,15(53.6 \%)$ and $13(46.4 \%)$ patients randomised to the original abatacept and placebo groups discontinued, respectively; $11(39.3 \%)$ and $12(42.9 \%)$ of these were owing to lack of efficacy. Seven $(25.0 \%)$ and four $(14.3 \%)$ patients randomised to abatacept and placebo completed 2 years, respectively.

\section{Development of rheumatoid arthritis by the ACR 1987 criteria}

Over 1 year, six patients discontinued without developing RA for reasons other than lack of efficacy, and were not included in the primary efficacy analysis (prespecified). Therefore, 50/56 patients were evaluable; 26 and 24 were treated with abatacept and placebo, respectively. At year 1 (6 months after treatment discontinuation), 12/26 (46.2\%) abatacept-treated and 16/24 (66.7\%) placebo-treated patients had been diagnosed with RA as defined by the ACR criteria. ${ }^{4}$ The CIs for the difference between the two groups included zero (difference (95\% CI) $-20.5 \%$ $(-47.4 \%$ to $7.8 \%))$; therefore, the primary end point for this trial was not met.

\section{Radiographic progression}

Adjusted mean (standard error (SE)) changes from baseline to month 6 in abatacept- versus placebo-treated patients were 0.15 (0.17) versus $0.46(0.18)$ for TS, $0.14(0.17)$ versus $0.45(0.18)$ for ES and $0(0)$ versus 0.01 (0) for JSN scores, respectively (figs 2A, $B$ and $C$, respectively). Adjusted mean (SE) changes from baseline to year 1 ( 6 months after treatment cessation) in abatacept- versus placebo-treated patients were $0.01(0.29)$ versus 1.11 (0.36) for TS, $0.01(0.20)$ versus 0.86 (0.25) for ES and $0(0.11)$ versus $0.26(0.14)$ for JSN scores, respectively. Estimates of difference $(95 \% \mathrm{CI})$ for abatacept versus placebo at year 1 were $-1.10(-2.05$ to -0.15$)$ for TS, $-0.84(-1.51$ to -0.18 ) for ES and -0.26 ( -0.63 to 0.11 ) for JSN scores. Confidence intervals did not include zero for either TS or ES. While radiographic assessments continued up to year 2, small patient numbers at this time point meant analysis of mean changes from baseline were not meaningful after year 1 .

\section{Magnetic resonance imaging}

Eleven abatacept- and 10 placebo-treated patients were eligible for MRI assessments. Osteitis scores improved from baseline to month 6 with abatacept (mean (SE) change -1.64 (1.48)), but deterioration was observed with placebo (1.40 (1.59)). For patients who remained in the trial at year 1, there was little progression in osteitis score in the abatacept group ( $n=9$; change of $0.22(0.49)$ from baseline). In the placebo group 
Table 2 Mean changes in serum anti-cyclic citrullinated peptide (CCP) and rheumatoid factor (RF) levels

\begin{tabular}{|c|c|c|}
\hline & Abatacept & Placebo \\
\hline \multicolumn{3}{|l|}{ Serum anti-CCP (U/ml) } \\
\hline Baseline (month 6 analysis) ${ }^{*}$ & $227.6(289.8)$ & $145.5(98.2)$ \\
\hline Month 6* & $133.1(198.2)$ & $161.9(155.3)$ \\
\hline Mean change from baseline to month $6(95 \% \mathrm{Cl})^{*}$ & $-94.5(-156$ to -33.0$)$ & $16.3(-28.8$ to 61.5$)$ \\
\hline Baseline (year 1 analysis) $\uparrow$ & $270.0(325.4)$ & $212.9(131.3)$ \\
\hline Year $1 \dagger$ & $263.5(430.0)$ & $362.4(314.2)$ \\
\hline Mean change from baseline to year $1(95 \% \mathrm{Cl}) \dagger$ & $-6.5(-110$ to 97.4$)$ & 149.5 (3.8 to 295.1 ) \\
\hline \multicolumn{3}{|l|}{ Serum RF (U/ml) } \\
\hline Baseline (month 6 analysis) $\$$ & $167.5(249.8)$ & $63.5(92.0)$ \\
\hline Month 6* & $42.4(46.3)$ & $61.5(82.9)$ \\
\hline Mean change from baseline to month $6(95 \% \mathrm{Cl}) \%$ & $-125(-218$ to -32.1$)$ & $-2.0(-15.4$ to 11.5$)$ \\
\hline Baseline (year 1 analysis)§ & $137.0(212.1)$ & $54.9(51.5)$ \\
\hline Year $1 \S$ & $96.3(109.7)$ & $47.1(53.9)$ \\
\hline Mean change from baseline to year $1(95 \% \mathrm{Cl}) \S$ & $-40.7(-133.0$ to 51.3$)$ & $-7.8(-35.2$ to 19.6$)$ \\
\hline
\end{tabular}

${ }^{*} \mathrm{n}=21$ and $19 ; \dagger \mathrm{n}=14$ and $10 ; \hbar n=22$ and $20 ; \xi n=15$ and 10 , for abatacept and placebo, respectively.

$(n=6)$, however, osteitis scores worsened by 6.67 (4.22) from baseline. MRI erosion and synovitis scores showed a similar trend; at month 6, mean changes from baseline were $0.45(0.37)$ and $0.27(0.56)$, respectively, in the abatacept group, and 1.20 (1.09) and 1.60 (1.23) in the placebo group. By year 1, mean change from baseline in erosion and synovitis scores were 0 $(0.17)$ and $0.22(0.22)$, respectively, in the abatacept group versus 5.00 (3.20) and 2.33 (1.61) in the placebo group.

\section{Biomarkers}

All patients were positive for anti-CCP2 antibodies at baseline. The percentage of anti-CCP2-positive patients declined in the abatacept group to $90.9 \%(20 / 22)$ at month 6 , and $86.7 \%$ $(13 / 15)$ at year 1 , while in the placebo group, all patients remained positive at month $6(19 / 19)$ and year $1(10 / 10)$. These data are consistent with results for changes in serum levels of anti-CCP2 antibodies (table 2).

At baseline, 85.7 and $71.4 \%$ of patients in the abatacept and placebo groups were positive for RF. The proportion of RFpositive patients at month 6 and year 1 was $59.1 \%(13 / 22)$ and $73.3 \%(11 / 15)$, respectively, in the abatacept group, and $70.0 \%$ $(14 / 20)$ and $80.0 \%(8 / 10)$ in the placebo group. Table 2 shows the mean changes in RF levels.

\section{Clinical efficacy}

Figure 3A shows a Kaplan-Meier curve of discontinuations due to lack of efficacy over 2 years; the median times to discontinuation were 507 and 344 days in the abatacept and placebo groups, respectively. After 6 months, $71.4 \%$ (15/21) versus $35.0 \%(7 / 20)$ of patients were in DAS28-defined remission for the abatacept versus placebo groups, respectively (fig 3B); at year 1 (following cessation of treatment for 6 months), the proportion of patients in DAS28-defined remission was $47.4 \%(9 / 19)$ versus $38.5 \%(5 / 13)$. At 6 months, the proportion of patients with zero swollen and tender joints was $62.5 \%(15 / 24)$ versus $14.3 \%(3 / 21)$, for the abatacept versus placebo groups, respectively; the proportion was $30.0 \%(6 / 20)$ versus $14.3 \%(2 / 14)$ at year 1 (fig 3C).

\section{Concomitant steroid use}

During the 6-month treatment period, $17.9 \%$ of patients in each group were receiving low-dose ( $<10 \mathrm{mg}$ prednisone equivalent) oral corticosteroids; in these patients, the mean (SD) dose was $4.8(1.8) \mathrm{mg} /$ day in the abatacept group and $6.0(1.4) \mathrm{mg} /$ day in the placebo group. From month 6 to year 2, 17.9 and $25.0 \%$ of patients in the abatacept and placebo groups were receiving low-dose oral corticosteroids, at a mean (SD) dose of 4.3 (1.2) and $6.0(1.3) \mathrm{mg} /$ day, respectively.

\section{Safety}

Table 3 summarises safety data over the 6-month treatment period plus 56-day follow-up after last dose of the study drug. Adverse events (AEs) were reported in 18 (64.3\%) abatacepttreated versus $20(71.4 \%)$ placebo-treated patients. The most frequently reported AEs (more than two patients in either group) were diarrhoea, nasopharyngitis, urinary tract infection, gastroenteritis, pharyngolaryngeal pain and headache. One abatacept-treated patient (3.6\%) discontinued owing to dyspnoea, and one placebo-treated patient (3.6\%) discontinued owing to thrombocytopenia. Serious AEs were reported in one patient $(3.6 \%)$ in each group. One was a basal cell carcinoma reported in a 74-year-old abatacept-treated patient (the only malignancy reported). The other was a case of lumbar sciatica in the placebo group. There were no reports of treatment-related serious AEs or discontinuations due to serious AEs. Infections were reported in 10 (35.7\%) abatacept-treated and 11 (39.3\%) placebo-treated patients. The most frequently reported infections ( $>10 \%$ overall) were nasopharyngitis (three abatacept vs two placebo patients), urinary tract infection (two abatacept vs three placebo patients) and gastroenteritis (no abatacept vs three placebo patients). Acute (within $1 \mathrm{~h}$ ) infusional reaction was reported in one patient $(3.6 \%)$ in each group, and peri(within $24 \mathrm{~h}$ ) infusional reactions were reported in two (7.1\%) and three $(10.7 \%)$ patients in the abatacept and placebo groups, respectively. No deaths occurred in either group.

\section{DISCUSSION}

This exploratory study examined the impact of abatacept in a subset of poor prognosis patients with UA or very early RA. Although abatacept monotherapy did not prevent development of RA by the ACR 1987 criteria at 1 year (and therefore the primary end point was not met), it impacted radiographic and MRI progression for $\geqslant 6$ months after the cessation of treatment. A reduction in the level of anti-CCP antibodies was seen after 6 months that was still evident at year 1 . This is the first study to demonstrate the efficacy of T-cell costimulation modulation with abatacept in a population of patients with UA or very early RA. The efficacy benefits observed with abatacept monotherapy were coupled with acceptable safety. 


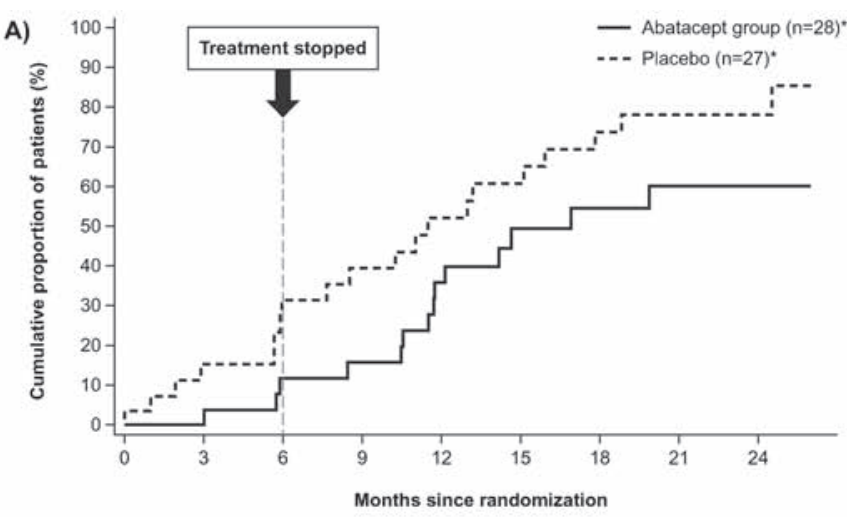

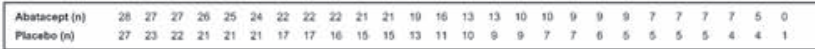

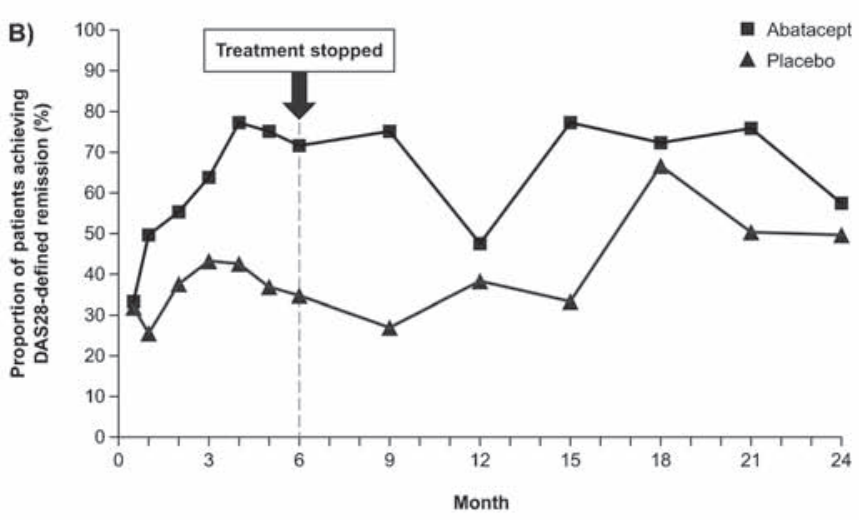

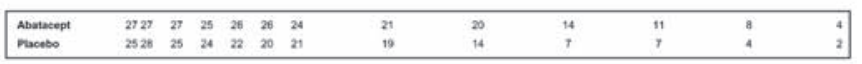

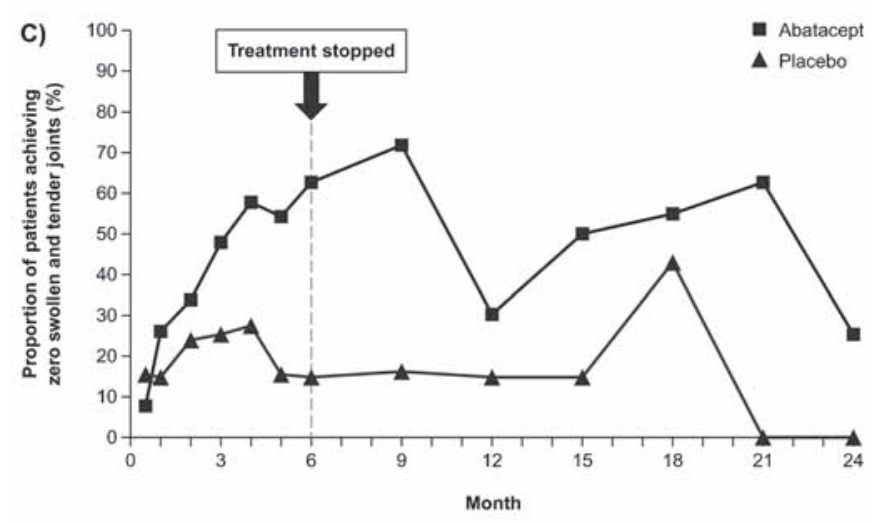

\begin{tabular}{|lllllllllllll|}
\hline Abatasept & 2727 & 27 & 25 & 26 & 26 & 24 & 21 & 20 & 14 & 11 & 8 & 4 \\
Macateo & 2528 & 25 & 24 & 22 & 20 & 21 & 19 & 14 & 7 & 7 & 4 & 2 \\
\hline
\end{tabular}

Figure 3 Clinical efficacy. (A) Kaplan-Meier plot showing the proportion of patients who discontinued owing to lack of efficacy over 2 years. One patient was diagnosed with RA at baseline and was excluded from the analyses; *Patients who discontinued for reasons other than lack of efficacy were censored at the time of discontinuation.

(B) Proportion of patients achieving DAS28-defined remission over 2 years. (C) Proportion of patients with zero swollen and tender joints over 2 years. DAS28, 28 joint count Disease Activity Score.

The reduction in anti-CCP2 levels observed after 6 months of abatacept treatment is suggestive of an effect on the underlying autoimmune process. Anti-CCP2 antibodies are highly predictive of the development of RA and, although not formally validated to assess disease activity, reductions in anti-CCP2 have been linked to improvements in clinical status in patients given biological treatments. ${ }^{21}{ }^{22}$ This is consistent with the effect
Table 3 Summary of safety over the 6-month treatment period*

\begin{tabular}{lcc}
\hline & $\begin{array}{c}\text { Abatacept } \\
(\mathbf{n = 2 8})\end{array}$ & $\begin{array}{c}\text { Placebo } \\
(\mathbf{n}=\mathbf{2 8})\end{array}$ \\
\hline AEs, $\mathrm{n}(\%)$ & $18(64.3)$ & $20(71.4)$ \\
$\quad$ Discontinuations due to AEs & $1(3.6)$ & $1(3.6)$ \\
Serious AEs, $\mathrm{n}(\%)$ & $1(3.6)$ & $1(3.6)$ \\
$\quad$ Discontinuations due serious AEs & 0 & 0 \\
Infections, $\mathrm{n}(\%)$ & $10(35.7)$ & $11(39.3)$ \\
Malignancies, $\mathrm{n}(\%)$ & $1(3.6)$ & 0 \\
Deaths, $\mathrm{n}(\%)$ & 0 & 0 \\
\hline
\end{tabular}

*Including a follow-up period of up to 56 days after the last dose of study drug.

$A E$, adverse event.

on radiological damage that persisted beyond cessation of active treatment, which suggests that the impact of abatacept may be most substantial at the primary site of disease, affecting early synovitis. This is further supported by the inhibition of osteitis, the presence of which is strongly predictive of subsequent radiographic progression in patients with early $R A .^{23}$ These data support the concept of a therapeutic window, during which the course of disease may be altered, ${ }^{12}$ and several lines of evidence indicate a key role for abatacept in the inhibition of structural damage. Synovial biopsy data from abatacept-treated patients with RA are consistent with a regulatory role of abatacept in osteoclast differentiation and bone resorption, ${ }^{24}$ and recent data ${ }^{25}$ have demonstrated that abatacept can directly inhibit the differentiation of osteoclast precursors, suggesting a further mechanism for the inhibition of erosion observed here.

Based on a Kaplan-Meier analysis, the cumulative rate of progression to RA (defined by the ACR 1987 criteria $^{15}$ ) was lower in the abatacept than the placebo group throughout the 2-year study. Rates of DAS28-defined remission were more than twofold greater in the abatacept than placebo groups at month 6. Although the DAS28 has been validated in patients with RA, ${ }^{26}$ it has not been validated in patients with UA, so swollen and tender joint counts may be a more clinically relevant assessment in these patients; the proportion of patients with zero swollen and tender joints was fivefold greater in the abatacept versus placebo groups at month 6 . For both of these efficacy measures, rates remained higher in the original abatacept versus placebo group at year 1, despite treatment cessation.

Although the patients in this trial did not have RA as defined by the ACR 1987 criteria, approximately half already exhibited evidence of erosions at baseline, and it is likely that a significant proportion had early RA. At the time this study was designed (2004), a diagnosis of UA required the presence of inflammatory arthritis in patients not satisfying the ACR 1987 criteria for RA ${ }^{15}$ or any other rheumatic disease. However, owing to the low discriminative ability of the ACR criteria in patients with recent-onset arthritis, ${ }^{27}$ it is generally accepted that patients may have early RA even if they do not meet the ACR 1987 criteria. Consequently, there is currently uncertainty around the terminology and classification of this group of patients, and the ACR criteria for early disease are currently under revision. It should also be noted that although the ACR criteria are commonly used in RA clinical trials, they do not represent a definitive diagnostic tool to assess the development of RA; it is likely that a number of patients included in this study may have actually been diagnosed with RA in clinical practice. Therefore, the "window of opportunity" for early treatment may have already passed for some patients. 
Some limitations must be considered when interpreting these findings. In this exploratory trial, patient numbers were low and formal statistical hypothesis testing was not performed. Although the primary end point of the trial was not met, it is possible that significance might have been observed in a larger sample with greater statistical power. Over-time analysis of the primary end point (RA defined by the ACR criteria ${ }^{15}$ ) was not possible owing to the requirement for radiographic assessment. Although discontinuation due to lack of efficacy allowed estimation of time to RA development, "lack of efficacy" was defined by the treating doctor and so may not have been completely aligned with development of RA according to the ACR criteria. ${ }^{15}$ Finally, the small number of patients remaining in the study over time meant that analysis of efficacy data was not meaningful in the second year.

In summary, abatacept reduced anti-CCP antibody levels and maintained the inhibition of radiographic and MRI progression for $\geqslant 6$ months after treatment cessation in patients with UA or very early RA. Studies in larger patient populations will help to confirm these findings. These data suggest that it is possible to alter the progression of RA by modulating $\mathrm{T}$-cell responses at a very early stage in disease.

Acknowledgements The authors would like to thank Medicus International for their editorial assistance. This study and the editorial assistance provided by Medicus International were funded by Bristol-Myers Squibb, Princeton, New Jersey, USA.

Funding This study was funded by Bristol-Myers Squibb.

Competing interests PE has received consulting fees, lecture fees and research grants from Bristol-Myers Squibb; PD has received lecture fees from Bristol-Myers Squibb; MD has received consulting fees, lecture fees and research grants from Bristol-Myers Squibb; CWL has received corporate funding for research protocols from Bristol-Myers Squibb, UCB Pharma, Pfizer, Roche, Genentech, Amgen, Abbott, Merck and Centocor; J-CB is employed by, and has restricted stocks with, Bristol-Myers Squibb; at the time of submission, GV was employed by, was a holder of a patent with and had stock options with, Bristol-Myers Squibb; HKG has received consulting fees and research grants from Bristol-Myers Squibb, and is a stockholder, board member and consultant to Synarc; CP is an employee of Synarc; PM is employed by BristolMyers Squibb; SO is employed by, and has stock options with, Bristol-Myers Squibb; K Qi is employed by and has stock options with Bristol-Myers Squibb; RW has received consulting fees from Bristol-Myers Squibb and Schering-Plough, a research grant from UCB, and lecture fees from Bristol-Myers Squibb.

Ethics approval Approval was received from several ethics committees.

Patient consent Patient consent received.

Provenance and peer review Not commissioned; externally peer reviewed.

\section{REFERENCES}

1. Goekoop-Ruiterman YP, de Vries-Bouwstra JK, Allaart CF, et al. Clinical and radiographic outcomes of four different treatment strategies in patients with early rheumatoid arthritis (the BeSt study): a randomized, controlled trial. Arthritis Rheum 2008;58(Suppl):S126-35.

2. Emery P, Breedveld FC, Hall S, et al. Comparison of methotrexate monotherapy with a combination of methotrexate and etanercept in active, early, moderate to severe rheumatoid arthritis (COMET): a randomised, double-blind, parallel treatment trial. Lancet 2008;372:375-82.

3. Grigor C, Capell H, Stirling A, et al. Effect of a treatment strategy of tight control for rheumatoid arthritis (the TICORA study): a single-blind randomised controlled trial. Lancet 2004;364:263-9.

4. van der Helm-van Mil AH, Verpoort KN, Breedveld FC, et al. The HLA-DRB1 shared epitope alleles are primarily a risk factor for anti-cyclic citrullinated peptide antibodies and are not an independent risk factor for development of rheumatoid arthritis. Arthritis Rheum 2006;54:1117-21.
5. Huizinga TW, Amos $\mathrm{Cl}$, van der Helm-van Mil AH, et al. Refining the complex rheumatoid arthritis phenotype based on specificity of the HLA-DRB1 shared epitope for antibodies to citrullinated proteins. Arthritis Rheum 2005;52:3433-8.

6. van Dongen $\mathbf{H}$, van Aken J, Lard LR, et al. Efficacy of methotrexate treatment in patients with probable rheumatoid arthritis: a double-blind, randomized, placebocontrolled trial. Arthritis Rheum 2007:56:1424-32.

7. Saleem B, Mackie S, Quinn M, et al. Does the use of TNF antagonist therapy in poor prognosis, undifferentiated arthritis prevent progression to rheumatoid arthritis? Ann Rheum Dis 2008;67:1178-80.

8. Janossy G, Panayi G, Duke 0, et al. Rheumatoid arthritis: a disease of T-lymphocyte/ macrophage immunoregulation. Lancet 1981;2:839-42.

9. van Boxel JA, Paget SA. Predominantly T-cell infiltrate in rheumatoid synovial membranes. N Engl J Med 1975;293:517-20.

10. Mima T, Saeki Y, Ohshima S, et al. Transfer of rheumatoid arthritis into severe combined immunodeficient mice. The pathogenetic implications of T cell populations oligoclonally expanding in the rheumatoid joints. J Clin Invest 1995;96:1746-58.

11. Sakata A, Sakata K, Ping H, et al. Successful induction of severe destructive arthritis by the transfer of in vitro-activated synovial fluid T cells from patients with rheumatoid arthritis (RA) in severe combined immunodeficient (SCID) mice. Clin Exp Immunol 1996;104:247-54.

12. Raza K, Falciani F, Curnow SJ, et al. Early rheumatoid arthritis is characterized by a distinct and transient synovial fluid cytokine profile of $T$ cell and stromal cell origin. Arthritis Res Ther 2005;7:R784-95.

13. Chambers CA, Kuhns MS, Allison JP. Cytotoxic T lymphocyte antigen-4 (CTLA-4) regulates primary and secondary peptide-specific CD4(+) T cell responses. Proc Natl Acad Sci USA 1999;96:8603-8.

14. Kliwinski C, Kukral D, Postelnek J, et al. Prophylactic administration of abatacept prevents disease and bone destruction in a rat model of collagen-induced arthritis. J Autoimmun 2005;25:165-71.

15. Arnett FC, Edworthy SM, Bloch DA, et al. The American Rheumatism Association 1987 revised criteria for the classification of rheumatoid arthritis. Arthritis Rheum 1988;31:315-24.

16. Clinicaltrials.gov. Study of abatacept versus placebo to assess the prevention of rheumatoid arthritis (RA) in adult patients. http://clinicaltrials.gov/ct2/show/ NCT00124449?term =abatacept\&recr=closed\&cond = undifferentiated+arthritis $\&$ rank $=1$ (accessed November 2009).

17. Genant HK. Methods of assessing radiographic change in rheumatoid arthritis. Am J Med 1983;75:35-47.

18. Genant HK, Peterfy CG, Westhovens R, et al. Abatacept inhibits progression of structural damage in rheumatoid arthritis: results from the long-term extension of the AlM trial. Ann Rheum Dis 2008;67:1084-9.

19. Ostergaard M, Peterfy $\mathbf{C}$, Conaghan $\mathrm{P}$, et al. OMERACT rheumatoid arthritis magnetic resonance imaging studies. Core set of MRI acquisitions, joint pathology definitions, and the OMERACT RA-MRI scoring system. J Rheumatol 2003;30:1385-6.

20. Anonymous. StatXact (Cytel). Available at http://www.cytel.com/products/statxact/ StatXact brochure.pdf and http://www.cytel.com/products/statxact/ laccessed November 2009)

21. Cuchacovich M, Catalan D, Wainstein E, et al. Basal anti-cyclic citrullinated peptide (anti-CCP) antibody levels and a decrease in anti-CCP titres are associated with clinical response to adalimumab in rheumatoid arthritis. Clin Exp Rheumatol 2008;26:1067-73.

22. Alessandri C, Bombardieri M, Papa N, et al. Decrease of anti-cyclic citrullinated peptide antibodies and rheumatoid factor following anti-TNFalpha therapy (infliximab) in rheumatoid arthritis is associated with clinical improvement. Ann Rheum Dis 2004;63:1218-21.

23. Hetland ML, Ejbjerg B, Horslev-Petersen K, et al. MRI bone oedema is the strongest predictor of subsequent radiographic progression in early rheumatoid arthritis. Results from a 2-year randomised controlled trial (CIMESTRA). Ann Rheum Dis 2009;68:384-90.

24. Buch MH, Boyle DL, Rosengren S, et al. Mode of action of abatacept in rheumatoid arthritis patients having failed tumour necrosis factor blockade: a histological, gene expression and dynamic magnetic resonance imaging pilot study. Ann Rheum Dis 2009;68:1220-7.

25. Axmann R, Herman S, Zaiss M, et al. CTLA-4 directly inhibits osteoclast formation. Ann Rheum Dis 2008:67:1603-9.

26. Wells G, Becker JC, Teng J, et al. Validation of the Disease Activity Score 28 (DAS28) and EULAR response criteria based on CRP against disease progression in patients with rheumatoid arthritis, and comparison with the DAS28 based on ESR. Ann Rheum Dis 2009;68:954-60.

27. Harrison BJ, Symmons DP, Barrett EM, et al. The performance of the 1987 ARA classification criteria for rheumatoid arthritis in a population based cohort of patients with early inflammatory polyarthritis. American Rheumatism Association. J Rheumatol 1998;25:2324-30. 


\section{Corrections}

The department of one of the authors who co-authored all of the below papers has found that the affiliations were not correct. The correct affiliations for Professor P Emery, for all of the below articles, are: ${ }^{1}$ Section of Musculoskeletal Disease, Leeds Institute of Molecular Medicine, University of Leeds; ${ }^{2}$ NIHR Leeds Musculoskeletal Biomedical Research Unit, Leeds Teaching Hospitals Trust, Leeds, UK.

1. Keystone E, Emery P, Peterfy CG, et al. Rituximab inhibits structural joint damage in patients with rheumatoid arthritis with an inadequate response to tumour necrosis factor inhibitor therapies. Ann Rheum Dis 2009;68:216-21.

2. Doward LC, McKenna SP, Whalley D, et al. The development of the L-OoL: a quality-of-life instrument specific to systemic lupus erythematosus. Ann Rheum Dis 2009;68:196-200.

3. Potter C, Hyrich KL, Tracey A, et al. Association of rheumatoid factor and anticyclic citrullinated peptide positivity, but not carriage of shared epitope or PTPN22 susceptibility variants, with anti-TNF response in RA. Ann Rheum Dis 2009;68:69-74.

4. Smolen JS, Han C, van der Heijde DM, et al.; Active-Controlled Study of Patients Receiving Infliximab for the Treatment of Rheumatoid Arthritis of Early Onset (ASPIRE) Study Group. Radiographic changes in rheumatoid arthritis patients attaining different disease activity states with methotrexate monotherapy and infliximab plus methotrexate: the impacts of remission and tumour necrosis factor blockade. Ann Rheum Dis 2009;68:823-7.

5. Buch MH, Boyle DL, Rosengren S, et al. Mode of action of abatacept in rheumatoid arthritis patients having failed tumour necrosis factor blockade: a histological, gene expression and dynamic magnetic resonance imaging pilot study. Ann Rheum Dis 2009;68:1220-7.

6. Emery P, Van Vollenhoven R, Ostergaard M, et al. Guidelines for initiation of antitumour necrosis factor therapy in rheumatoid arthritis: similarities and differences across Europe. Ann Rheum Dis 2009;68:456-9.

7. Bejarano V, Conaghan PG, Proudman SM, et al. Long-term efficacy and toxicity of ciclosporin A in combination with methotrexate in poor prognosis rheumatoid arthritis Ann Rheum Dis 2009;68:761-3.

8. Rudwaleit M, Landewé R, van der Heijde D, et al. The development of Assessment of SpondyloArthritis international Society classification criteria for axial spondyloarthritis (part I): classification of paper patients by expert opinion including uncertainty appraisal. Ann Rheum Dis 2009;68:770-6.

9. Bennett AN, Marzo-Ortega H, Emery P, et al.; Leeds Spondyloarthropathy Group. Diagnosing axial spondyloarthropathy. The new Assessment in SpondyloArthritis international Society criteria: MRI entering centre stage. Ann Rheum Dis 2009;68:765-7.

10. Marzo-Ortega H, McGonagle D, O'Connor P, et al. Baseline and 1-year magnetic resonance imaging of the sacroiliac joint and lumbar spine in very early inflammatory back pain. Relationship between symptoms, HLA-B27 and disease extent and persistence. Ann Rheum Dis 2009;68:1721-7.

11. Gilworth G, Emery P, Gossec L, et al. Adaptation and cross-cultural validation of the rheumatoid arthritis work instability scale (RA-WIS). Ann Rheum Dis 2009;68:1686-90.

12. Gilworth G, Emery P, Gossec L, et al. Adaptation and cross-cultural validation of the RA-WIS (Work Instability Scale). Ann Rheum Dis 2009;68:1686-90.

13. Jarrett SJ, Sivera F, Cawkwell LS, et al. MRI and clinical findings in patients with ankylosing spondylitis eligible for anti-tumour necrosis factor therapy after a short course of etoricoxib. Ann Rheum Dis 2009;68:1466-9.

14. Haugeberg G, Conaghan PG, Quinn $\mathrm{M}$, et al. Bone loss in patients with active early rheumatoid arthritis: infliximab and methotrexate compared with methotrexate treatment alone. Explorative analysis from a 12-month randomised, double-blind, placebo-controlled study. Ann Rheum Dis 2009;68:1898-901.

15. Genovese MC, Breedveld FC, Emery P, et al. Safety of biological therapies following rituximab treatment in rheumatoid arthritis patients. Ann Rheum Dis 2009;68:1894-7

16. Kekow J, Moots RJ, Emery P, et al. Patient-reported outcomes improve with etanercept plus methotrexate in active early rheumatoid arthritis and the improvement is strongly associated with remission: the COMET trial. Ann Rheum Dis 2010;69:222-5

17. Furst DE, Keystone EC, Fleischmann R, et al. Updated consensus statement on biological agents for the treatment of rheumatic diseases, 2009. Ann Rheum Dis 2010;69(Suppl 1):i2-29.

18. Freeston JE, Wakefield RJ, Conaghan PG, et al. A diagnostic algorithm for persistence of very early inflammatory arthritis: the utility of power Doppler ultrasound when added to conventional assessment tools. Ann Rheum Dis 2010;69:417-9.

19. Jones $\mathbf{E}$, Churchman SM, English A, et al. Mesenchymal stem cells in rheumatoid synovium: enumeration and functional assessment in relation to synovial inflammation level. Ann Rheum Dis 2010;69:450-7.

20. Alten RE, Zerbini C, Jeka S, et al. Efficacy and safety of pamapimod in patients with active rheumatoid arthritis receiving stable methotrexate therapy. Ann Rheum Dis 2010;69:364-7.
21. Machold KP, Landewé R, Smolen JS, et al. The Stop Arthritis Very Early (SAVE) trial, an international multicentre, randomised, double-blind, placebo-controlled trial on glucocorticoids in very early arthritis. Ann Rheum Dis 2010;69:495-502.

22. Schoels M, Knevel R, Aletaha D, et al. Evidence for treating rheumatoid arthritis to target: results of a systematic literature search. Ann Rheum Dis 2010;69:638-43.

23. Smolen JS, Aletaha D, Bijlsma JW, et al.; T2T Expert Committee. Treating rheumatoid arthritis to target: recommendations of an international task force. Ann Rheum Dis 2010;69:631-7.

24. Burr ML, Naseem H, Hinks A, et al.; BIRAC Consortium; YEAR Consortium. PADI4 genotype is not associated with rheumatoid arthritis in a large UK Caucasian population. Ann Rheum Dis 2010;69:666-70.

25. Emery $\mathbf{P}$, Durez P, Dougados $\mathrm{M}$, et al. Impact of T-cell costimulation modulation in patients with undifferentiated inflammatory arthritis or very early rheumatoid arthritis: a clinical and imaging study of abatacept (the ADJUST trial). Ann Rheum Dis 2010;69:510-16.

26. Bennett AN, Rehman A, Hensor EM, et al. The fatty Romanus lesion: a noninflammatory spinal MRI lesion specific for axial spondyloarthropathy. Ann Rheum Dis 2010;69:891-4.

27. Nam JL, Winthrop KL, van Vollenhoven RF, et al. Current evidence for the management of rheumatoid arthritis with biological disease-modifying antirheumatic drugs: a systematic literature review informing the EULAR recommendations for the management of RA. Ann Rheum Dis 2010;69:976-86.

28. Smolen JS, Landewé R, Breedveld FC, et al. EULAR recommendations for the management of rheumatoid arthritis with synthetic and biological disease-modifying antirheumatic drugs. Ann Rheum Dis 2010;69:964-75.

29. Tan RJ, Gibbons LJ, Potter C, et al.; BRAGGSS. Investigation of rheumatoid arthritis susceptibility genes identifies association of AFF3 and CD226 variants with response to anti-tumour necrosis factor treatment. Ann Rheum Dis 2010;69:1029-35.

30. Robinson JI, Barrett JH, Taylor JC, et al.; YEAR Consortium; BRAGGSS. Dissection of the FCGR3A association with RA: increased association in men and with autoantibody positive disease. Ann Rheum Dis 2010;69:1054-7.

31. Cohen SB, Keystone E, Genovese MC, et al. Continued inhibition of structural damage over 2 years in patients with rheumatoid arthritis treated with rituximab in combination with methotrexate. Ann Rheum Dis 2010;69:1158-61.

32. Haugeberg G, Bennett AN, McGonagle D, et al. Bone loss in very early inflammatory back pain in undifferentiated spondyloarthropathy: a 1-year observational study. Ann Rheum Dis 2010;69:1364-6.

33. Schoels M, Aletaha D, Smolen JS, et al. Follow-up standards and treatment targets in rheumatoid arthritis: results of a questionnaire at the EULAR 2008. Ann Rheum Dis 2010;69:575-8

34. Eyre S, Flynn E, Martin P, et al. No evidence for association of the KLF12 gene with rheumatoid arthritis in a large UK cohort. Ann Rheum Dis 2010;69:1407-8.

35. Eyre S, Hinks A, Flynn E, et al. Confirmation of association of the REL locus with rheumatoid arthritis susceptibility in the UK population. Ann Rheum Dis 2010;69:1572-3

36. Orozco G, Eyre S, Hinks A, et al.; Wellcome Trust Case Control consortium YEAR Consortium. Association of CD40 with rheumatoid arthritis confirmed in a large UK case-control study. Ann Rheum Dis 2010;69:813-16.

37. Emery $\mathbf{P}$, Durez P, Dougados $M$, et al. Impact of T-cell costimulation modulation in patients with undifferentiated inflammatory arthritis or very early rheumatoid arthritis: a clinical and imaging study of abatacept (the ADJUST trial). Ann Rheum Dis 2010;69:510-16

38. Saleem B, Keen $\mathrm{H}$, Goeb V, et al. Patients with RA in remission on TNF blockers: when and in whom can TNF blocker therapy be stopped? Ann Rheum Dis 2010;69:1636-42.

39. Barkham N, Coates LC, Keen H, et al. Double-blind placebo-controlled trial of etanercept in the prevention of work disability in ankylosing spondylitis. Ann Rheum Dis 2010;69:1926-8.

40. Emery P, Deodhar A, Rigby WF, et al. Efficacy and safety of different doses and retreatment of rituximab: a randomised, placebo-controlled trial in patients who are biological naive with active rheumatoid arthritis and an inadequate response to methotrexate (Study Evaluating Rituximab's Efficacy in MTX iNadequate rEsponders (SERENE)). Ann Rheum Dis 2010;69:1629-35.

41. Dixon WG, Hyrich KL, Watson KD, et al.; BSRBR Control Centre Consortium; British Society for Rheumatology Biologics Register. Influence of anti-TNF therapy on mortality in patients with rheumatoid arthritis-associated interstitial lung disease: results from the British Society for Rheumatology Biologics Register. Ann Rheum Dis 2010;69:1086-91. 